\title{
Business Retention and Expansion (BRE) Programs: Conducting Successful Business Retention and Expansion Visits ${ }^{1}$
}

Henry M. Cothran ${ }^{2}$

\section{Introduction}

In an effort to encourage the retention and expansion of existing businesses, many communities establish Business Retention and Expansion (BRE) programs. These programs are designed to demonstrate a community's appreciation for the businesses, and identify immediate needs, future plans, and opportunities for the community to deliver programs and services identified through a business survey process. BRE programs follow one of two approaches: (1) use volunteers or (2) use paid staff to oversee and implement the program. The common element of both approaches is the business visit. Business visits serve four general purposes: (1) introduce the BRE program staff, (2) provide information about available programs and services, (3) respond to specific requests, and (4) learn about business needs, plans, and attitudes of the community through a formal or informal survey. This publication describes the general guidelines for training teams to conduct successful business visits for both types of programs when the purpose of the visit is to conduct a formal survey. This publication is the fifth in a series of ten on establishing Business Retention and Expansion programs. The publications in this series can be found online at the EDIS website at http://edis.ifas.ufl.edu/TOPIC_SERIES_BRE.

\section{Identify the Purpose of the Visit}

Before embarking on a business visitation program it is necessary to determine the purpose of the visit, the method of collecting data, the number of firms to be visited and the time frame within which the visits will take place. Each of these determinations will influence who will participate in the visit and the number of people involved in the visitation process. If the purpose of the visit is to inform the business of the existence of a local BRE program, then the visit is often done by a single individual (usually an employee of an economic development organization, the Chamber of Commerce, or local utility company). If the purpose is to provide information about a particular program or service (e.g., a new worker training program), then the visit may involve representatives of the BRE program and the service provider(s). If the purpose of the visit is to collect information about the business

1. This is EDIS document FE655, a publication of the Food and Resource Economics Department, Florida Cooperative Extension Service, Institute of Food and Agricultural Sciences, University of Florida, Gainesville, FL. Published August 2006. Please visit the EDIS website at http://edis.ifas.ufl.edu.

2. Henry M. Cothran, Associate In, Food and Resource Economics Department, Florida Cooperative Extension Service, Institute of Food and Agricultural Sciences, University of Florida, Gainesville, FL.

The Institute of Food and Agricultural Sciences (IFAS) is an Equal Opportunity Institution authorized to provide research, educational information and other services only to individuals and institutions that function with non-discrimination with respect to race, creed, color, religion, age, disability, sex, sexual orientation, marital status, national origin, political opinions or affiliations. U.S. Department of Agriculture, Cooperative Extension Service, University of Florida, IFAS, Florida A. \& M. University Cooperative Extension Program, and Boards of County Commissioners Cooperating. Larry Arrington, Dean 
via a written survey instrument, then the general practice is to send a two-person team.

\section{Recruit Business Visitors}

As noted in the introduction, BRE programs may rely on volunteers or a paid staff. If the program uses volunteers, these may be recruited from a variety of sources, including economic, business, civic, social, and religious organizations. Some volunteer programs also use educators, elected officials, and representatives of government agencies. These volunteers are sought out because they are seen as community leaders based on their active involvement in community life. The volunteers are brought together for a limited time for the sole purpose of collecting data for a single survey and usually are not involved in a formal on-going economic development program.

Programs using paid staff utilize people involved in some aspect of economic development, either as employees of the local Economic Development Organization (EDO) or as service providers, such as the Work Force Development Board, technical schools, or community colleges. Partner organizations may assign staff to participate in the business visits as part of their normal work assignment, and the business visits are coordinated through the local EDO.

\section{Establish a Visitation Team}

While interviews may be conducted by a single individual, most organizations involved in business visits send a two-person team. One person is assigned to ask the survey questions and the other person is assigned to record the responses to the questions. The reasons for a two-person team are practical:

- People not involved in interviewing as a profession find it difficult to handle both tasks.

- The loss of eye contact when transitioning from asking a question to recording the answer makes it difficult to establish and maintain rapport with the person being interviewed.

- A separate recorder makes asking probing questions easier and ensures that the responses are complete.

\section{Train for Business Visits}

Athletic teams are successful if they recruit good team players, have a plan for winning, and train to carry out that plan. A successful business visitation program can be viewed in the same way: recruit the best people for participating in the visit, know in advance what the visitors are to accomplish and why, and train the visitors in the techniques of successful interviews. A training session for business visitors does not have to be a long or difficult process. The elements of a successful visit can be conveyed in a three-hour manadatory training session for everyone participating in the interview process. A typical survey training program has at least the following six components (Loveridge and Morse, 1998):

1. An explanation of the purpose of the survey.

2. An explanation of the role of the interview team.

3. A detailed review of the survey instrument.

4. Assignment of the teams to businesses for the actual interviews.

5. Training on interviewing and note-taking techniques.

6. A practice interview.

\section{Component 1. Purpose of the Survey}

The purpose of a business survey must be established before a visitation program is initiated. The purpose of the survey should guide the development of the survey questions, and a purpose statement should be included in the survey instrument used in the interview process. Two-person teams visiting businesses should be familiar with the purpose of the survey so that they both understand why they are conducting the interview and can explain the benefits of participating in the interview. The following are some typical purpose statements:

- Demonstrate the community's appreciation for its existing businesses.

- Identify immediate problems facing a business so that these problems can be addressed. 
- Identify perceptions of the community as a place to do business.

- Identify the training and technical assistance needs of the business.

- Identify the future plans of a business.

- Build community capacity for sustained growth and development.

\section{Component 2. Role of the Interview Team}

Simply put, the role of the interview team is to collect data and return that data to the local EDO for follow-up action. Though interviewing sounds like a simple task, a successful interview is the core of a project's success, and the importance of the interviewer/note-taker in the process should not be underestimated or taken lightly. An interviewer (or note-taker) who is unclear about or unsure of his role or who is not committed to the success of the project damages the credibility of the program and jeopardizes the overall chances of its successful completion. The team is responsible for knowing the survey and its purpose, understanding the answers provided by the business owners/operators, and identifying any potential areas of concern (sometimes called red flags) that should be addressed immediately by the EDO.

\section{Component 3. Review the Survey Instrument}

Business visitation training is not complete until the teams have been introduced to the survey instrument. Both members of the team must understand the intent of each question and know how each question fits into the overall survey and helps to achieve one or more of the stated purposes of the survey. Familiarity with the survey's purpose, question types, and answer formats helps the interviewers to accurately administer the survey. A detailed review of the survey instrument in a group setting allows team members to ask their own questions and to learn from the questions of others about the content and intent of the survey.

\section{Component 4. Assign Teams to Businesses for the Actual Interviews}

Deciding which team visits a particular business is a local decision that varies from community to community. Teams can choose the businesses they wish to visit, the program coordinator can make the choice, or a combination of the two approaches can be used. Addressing the following questions can help determine the appropriate approach for your program:

- What, if any, has been the past practice?

-What does the business owner/operator expect? (If the business owner/operator is used to seeing an economic development professional, then the team should use paid staff.)

- Would you allow interviewers to visit like businesses (competitors)?

- Does the interviewer see the visit as an opportunity for personal gain?

- Are the interview teams capable of and willing to make cold calls on businesses to set up interviews?

-Which approach is easiest from a project management perspective?

As a rule of thumb, visits, including travel time, take approximately two hours to complete. If the visits are part of the assigned duties of the team, then there is no practical reason, except for other responsibilities, to limit the number of assigned businesses. If, however, the teams are volunteers, it may be advisable to limit the number of assigned businesses to four or less. This equates to donating one work day to the project.

\section{Component 5. Interviewing and Note-taking Techniques}

Everyone involved in business visits should be required to attend at least one visitation training session. The purpose of the session is to familiarize the participants with the program, their role in the process, and information on good interviewing and note-taking techniques. Prior to training, each participant should be given a packet of materials containing: 
- Background on the project and survey purpose.

- Initial contact script.

- Guidelines for successful visits.

- A copy of any correspondence with the firms to be visited.

- A visitation checklist.

- The names and contact information for the assigned firms.

- The survey instrument.

The background on the project and purpose of the survey should clearly and concisely identify the survey sponsor or sponsors, why the survey is being conducted (the purpose statement), the intended use of the survey results, how the data will be presented, and any guidelines for the survey respondent. The confidential nature of the process must be stressed.

If the visitation team will be scheduling the business interview directly with the business owner/operator, it is useful to prepare a script for use in the initial contact. It should be stressed that the script should serve as a guide for the conversation and should not be read verbatim. The script should contain a brief statement on the project background. The confidential nature of the process should be included in the script, as well as any "rules" for conducting the interview. A common rule for interviews is called the "skip it" rule, which tells the business owner/operator that he may choose not to answer any question without providing a reason for non-response. This initial contact script can also be used again at the start of the formal interview process during the visit.

There should be guidelines for the two-person team for before the visit, during the visit, and after the visit, and individual guidelines for the interviewer and the note-taker.

\section{Team Guidelines Before the Visit}

- If the team is to schedule the business interview, call to schedule an interview as soon as possible after the training, but within the time limit set in the training; talk to the business owner/operator; and secure agreement to participate and set a date and time for the interview.

- Visit within the time limit set during the visitor training.

- Decide which member of the team will conduct the interview and which one will take notes.

- Review the materials from the visitation training.

- Practice the interview: be familiar with the survey purpose, the survey rules, and the survey questions, and know the name of the business, the nature of the business, and the name of the person you will be interviewing.

- Call the day before the interview to re-confirm the time and location of the visit.

- Arrive at the business slightly before the interview appointment is scheduled.

- If multiple interviews are scheduled on the same day, make sure you have allowed sufficient travel time between interviews. A good rule of thumb is to allow at least two hours for each interview.

- Make sure you have the business visitation packet for each interview you will be conducting.

- Inform the program sponsor (or some designated contact) if the business refuses to participate in the interview.

\section{Team Guidelines During the Visit}

- The interview should be viewed as a professional activity, not a social occasion. It is important to arrive on time, even a bit early. The business owner/operator may keep the interview team waiting, but the opposite should never occur.

- Dress appropriately. How you dress, just as how you act, reflects on the sponsoring organization and sends a message about the professionalism of the process. What you wear may depend on several factors, such as the business you are visiting, the location of the visit, and local customs. 
- Break the ice before the interview starts. Seek some common ground with the business owner/operator. Thank the owner for agreeing to participate in the survey.

- Make sure the person being interviewed has a copy of the questionnaire.

- Review the purpose of the program and go over the survey ground rules, paying particular attention to the "skip it" rule and the confidentiality of responses.

\section{Team Guidelines After the Visit}

- Compare notes. Make sure that both of you heard the same thing. If necessary, expand the notes based on your common recollections of the business owner/operator responses.

- Discuss any issues of immediate concern and note these and any other items, such as requests for information or a personal contact on the survey form.

- Return the questionnaire as soon as possible to the designated drop-off location.

\section{Interviewer Guidelines}

- Ask every question. The person being interviewed may elect not to answer a question, but the interviewer must ask every question in the questionnaire.

- Ask exactly as worded. Changing the wording of a question changes its meaning. It is all right to repeat a question but never appropriate to interpret the intent of a question. If the interviewee asks: "what does this mean," the appropriate response is to ask: "what do you think it means."

- Listen carefully. Allow the owner/operator time to think about a response.

- Never suggest answers! The sponsoring organization is not seeking the opinion of the interview team. It is looking for information from the business.
- Show a genuine interest in the responses. Acknowledge answers.

- Remember that a good interview technique results in good data.

- Probe for completeness. It is permissible to ask questions (e.g., "Would you mind telling us why you think ...?")

- Do not take offense or argue with the answers. Remember that you are there to collect data and not engage in debates.

- Do not promise solutions. As an interview team, you have no authority to address or resolve problems identified by the business owner/operator. You may promise that you will make the sponsoring organizations aware of the concerns and that someone will be in contact with the business to look into the problem.

- Do not forget the "skip it" rule.

\section{Note-taker Guidelines}

- Make sure you have an extra copy of the survey instrument and an extra pen for recording responses. In most survey programs, the business owner/operator will have received a copy of the survey instrument in advance, but it is always a good idea to have an extra copy on hand.

- Mark responses appropriately. Keep in mind that someone else will be taking the survey instrument and recording it in some sort of database for compilation and analysis. Be considerate of the data-entry operator and follow the directions on the survey as to how to mark answers

- Take complete notes and write legibly. Paraphrase long answers, if necessary, and then rewrite notes after the interview so that a more compete picture of the interview is presented.

- Ask for clarification if you do not understand a response. The role of the note-taker is not to engage in the conversation, but if you are unsure about a response or feel that you have not correctly recorded an answer, it is appropriate to 
ask for clarification or even to ask that the interview be paused while you catch up.

- Do no forget the "skip it" rule. If the interviewer skips a question, point it out. If the interviewee skips a question, make sure you skip the question in recording the responses.

\section{Component 6. Practice Business Visits}

"Practice makes perfect" goes an old adage. That is certainly true for business visits, and the best practice may be in the form of an actual interview. It is useful for prospective team members to participate in a real-life situation to see how business owners/operators interpret questions and respond to the interview process. Practice interviews may involve larger groups of interviewers since the purpose is to get a "feel" for how the interview process actually works. However, finding sufficient businesses to participate in practice interviews and the added training time are potential drawbacks to this approach.

An alternative to a practice business visit is to participate in a mock interview. Mock interviews can be very simple or fairly sophisticated. On the simple end, teams can practice with a third person who assumes the role of a business owner/operator. A more detailed and engaging approach is to provide a script for each of the participants, dictating specific actions during the interview process. A fourth person can act as an observer and critique the actions of the interviewer and note-taker at the conclusion of the mock interview. Although this process requires less time on the part of those training to do business visits, it will require time and creativity on the part of the trainer, who will have to write a variety of scripts for the various participants in the mock interview.

\section{Conclusion}

Successful business visits are the result of comprehensive training and preparation. This publication has outlined a process for that training and highlighted proven training tips for the people involved in the interview process. The interview guidelines presented in this publication were developed based on evaluating visitation programs in more than eighty communities. Following the approach outlined in this publication will enhance the chances of a successful program in your community.

\section{References}

Loveridge, Scott, and George Morse. 1998. Implementing Local Business Retention and Expansion Visitation Programs, Northeast Regional Center for Rural Development Publication No. 72. Penn State University, University Park, PA. [five booklets and a video] 